PAPER

\title{
Bilateral subthalamic nucleus stimulation improves balance control in Parkinson's disease
}

\author{
S Colnat-Coulbois, G C Gauchard, L Maillard, G Barroche, H Vespignani, J Auque, Ph P Perrin
}

See Editorial Commentary, p 759

J Neurol Neurosurg Psychiatry 2005;76:780-787. doi: 10.1136/jnnp.2004.047829

See end of article for authors' affiliations

.....................

Correspondence to: Professor P P Perrin, Equilibration et

Performance Motrice, UFR

STAPS, Université Henri

Poincaré-Nancy 1, 30, rue

du Jardin Botanique,

54600 Villers-lès-Nancy,

France; Philippe.Perrin@

staps.uhp-nancy.fr

Received 17 June 2004

Revised version received

2 September 2004

Accepted

13 September 2004

Background: Parkinson's disease (PD), the most common basal ganglia degenerative disease, affects balance control, especially when patients change balance strategy during postural tasks. Bilateral chronic stimulation of the subthalamic nucleus (STN) is therapeutically useful in advanced PD, and reduces the motor signs of patients. Nevertheless, the effects of STN stimulation on postural control are still debatable. Aims: To assess the impact of bilateral STN stimulation on balance control in PD and to determine how basal ganglia related sensorimotor modifications act on neurosensorial organisation of balance and motor postural programming.

Methods: Twelve subjects aged 45-70 years underwent unified Parkinson's disease rating scale motor (part III) clinical tests, static and dynamic posturography, including sensory organisation and adaptation tests, shortly before and six months after bilateral implantation of electrodes into the STN.

Results: The postoperative static test showed an improvement in postural control precision both in eyes open and eyes closed conditions. The dynamic test highlighted the decreased number of falls and the ability of the patients to develop more appropriate sensorimotor strategies when stimulated. The sensory organisation test showed an improvement of equilibrium score and, thus, a better resolution of sensorial conflicts.

Conclusions: STN stimulation allowed a reduction in rigidity and therefore an improvement in the ability to use muscular proprioception as reliable information, resulting in vestibulo-proprioceptive conflict suppression. STN stimulation has a synergistic effect with levodopa for postural control. Accordingly, non-dopaminergic pathways could be involved in postural regulation and STN stimulation may influence the functioning of these pathways.

$\mathrm{R}$ educed postural control is one of the most disabling symptoms in patients suffering from advanced Parkinson's disease $(\mathrm{PD}),{ }^{1}$ and is responsible for significant mortality and morbidity. This postural instability, described in upright stance, during static or dynamic tasks, is characterised mainly by the subject having difficulty in modulating the magnitude of the postural response, and so generating an accurate motor response. Peripheral inputs are affected differently in PD. Vestibular and proprioceptive functions are thought to be intact. ${ }^{2}$ However, at the central level of balance related information processing, tilting reactions are impaired and galvanic vestibular stimulation reactions are exaggerated, suggesting a central disruption of labyrinthine postural reactions. ${ }^{2}{ }^{3}$ Visual information is probably misinterpreted by the central centres. ${ }^{4}$ Although the proprioceptive pathways are intact in PD, several authors have demonstrated deterioration in proprioceptive regulation leading to inadequate postural responses. ${ }^{5-7}$ Bloem et al reported that abnormal postural responses in $\mathrm{PD}$ resulted in weaker stabilising forces at the ankle joint, delayed initiation of postural responses, and inability of the patients to change postural responses according to the body position and environmental conditions. ${ }^{8}$ This inability to adjust the gain of the different regulation loops is particularly obvious when patients with PD have to change balance strategy during a postural task. ${ }^{10}$ Balance instability seems to result from an alteration at the central information processing level, rather than dysfunction of inputs themselves. These data suggest the existence of a conflict in central information processing that could be the result of misinterpretation or misintegration of the correct peripheral inputs. This abnormal sensory processing of postural control may be an inherent property of central integration in PD. ${ }^{11}$ Moreover, cognitive functions are altered, ${ }^{12-14}$ such as those concerning voluntary motor preprogramming, ${ }^{15}$ working memory, ${ }^{16}$ and visuospatial organisation. ${ }^{17}$ This abnormal neuronal behaviour, transmitted to the thalamus, cortex, and brainstem, is thought to disrupt the functioning of the motor system. ${ }^{18}$ Abnormalities of sensorimotor integration and difficulties in the organisation of postural activities both contribute to postural instability, ${ }^{1}$ resulting in an increased risk of falls, ${ }^{19}$ all the more so because the fear of falling is an important contributive factor in $\mathrm{PD}^{20}$ and because patients with $\mathrm{PD}$ show a significantly increased dependence upon visual information, both perceptually and motorically. ${ }^{21}$

The influence of treatment for PD on balance control is controversial. Clinical evidence suggests that the reduction in rigidity and bradykinesia resulting from treatment with levodopa (L-dopa) should improve postural adjustments by increasing joint flexibility and reducing the reaction time required for an appropriate postural response. In this respect, Bejjani et al reported that L-dopa treatment could partially improve axial signs of PD, such as abnormal posture and postural instability. ${ }^{22}$ However, some studies have reported that balance control is poorly improved ${ }^{23}$ and may even be impaired by dopaminergic medications. ${ }^{112425}$ Functional neurosurgery provided new opportunities for the treatment

Abbreviations: $A D T$, adaptation test; $A P$, anterior-posterior; CoP, centre of foot pressure; CoG, centre of gravity; $\mathrm{df}$, degrees of freedom; $E C$, eyes closed; $E M G$, electromyographic; EO, eyes open; ES, equilibrium score; FFT, fast Fourier transformation; Lat, lateral sways; LDopa, levodopa; LLR, long latency response; MLR, medium latency response; MRI, magnetic resonance imagery; PD, Parkinson's disease; PPN, pedonculo-pontine nucleus; SLR, short latency response; SOT, sensory organisation test; SP, sway path; SS, strategy score; STN, subthalamic nucleus 
of advanced PD, by using several targets such as the ventral intermediate nucleus of the thalamus, the globus pallidus, or the subthalamic nucleus (STN). The effects of pallidotomy on postural control remain controversial and, although certain studies reported improvement in postural control, ${ }^{11} 2627$ axial symptoms usually return within a few months after surgery ${ }^{28}$ or may even be impaired immediately after surgery. ${ }^{29}$

Although chronic stimulation of STN was recognised to be the most appropriate target for motor symptoms, ${ }^{30}$ its influence on balance control is unclear. Clinical evaluations have reported a pronounced improvement in posture, from more than $60 \%$ for Benabid and colleagues ${ }^{31}$ to $76 \%$ for Bejjani et al. ${ }^{22}$ Bejjani et al noticed that the combination of STN stimulation and L-Dopa treatment had a synergistic effect on postural symptoms, which was not found for limb signs (akinesia, rigidity, and tremor). However, in a recent study of the preoperative clinical predictive factors, Welter et al concluded that postural instability contributed to unfavourable motor outcome after surgery, and had to be considered as an exclusion criterion for this type of treatment. $^{32}$ Few posturographic evaluations have been performed after deep brain stimulation. Rocchi and colleagues $^{25}$ showed an improvement in postural sway after STN and globus pallidus pars internalis stimulation, whereas Maurer et al reported parallel effects of L-Dopa and STN stimulation and an absence of improvement in postural control. ${ }^{33}$ In this controversial context, the aim of our study was to evaluate the influence of bilateral chronic STN stimulation in conjunction with L-Dopa on postural control in $\mathrm{PD}$, and to determine the sensorimotor strategy modifications generated at the central structure level for postural tasks requiring a high level of central information processing, such as dynamic posturographic or sensorial conflict tasks.

\section{METHODS \\ Patients}

Our study involved 12 patients with advanced PD who underwent surgery to position electrodes that would bilaterally stimulate the STN (five women and seven men; median age (M), 58.5 years at the time of the surgical procedure; first quartile $\left(\mathrm{Q}_{1}\right), 54.0$ years; third quartile $\left(\mathrm{Q}_{3}\right)$, 67.0 years). The median duration of the disease was 11.5 years $\left(Q_{1}, 9.7\right.$ years; $Q_{3}, 14.0$ years $)$. All patients showed a good response to L-Dopa, and none had contraindications to surgical treatment such as dementia, depression, or major abnormalities (severe atrophy, leucoencephalopathy, or multiple lacunae) detected by cerebral magnetic resonance imagery (MRI). All patients gave informed consent before data collection, and were examined by clinical and posturographic tests before (preoperative condition) and after surgery (postoperative condition).

\section{Surgical procedure}

Phase 1: MRI stereotactic targeting

The first part of the surgical procedure is performed under general anaesthesia. The stereotactic frame (Fischer ZDLeibninger, Freiburg, Germany) is positioned on the patient's head. Stereotactic MRI is then performed according to a protocol inspired by Bejjani et al, ${ }^{34}$ including a three dimensional stereotactic Tl weighted image sequence with injection of gadolinium and a frontal $\mathrm{T} 2$ coronal $\mathrm{T} 2$ weighted spin echo acquisition.

\section{Phase 2: determination of the coordinates of the target}

The coronal T2 weighted acquisition allows direct visualisation of the STN, which appears as a hyposignal located on a coronal section situated immediately in front of the red nucleus, above and lateral to the locus niger. The trajectories of the test electrodes are determined according to the following guidelines: (1) double obliquity avoiding the frontal horn of the lateral ventricle; (2) avoidance of vascular elements; and (3) respect of the tridimensional STN geometry to ensure that the trajectories cross the longest part of the structure.

\section{Phase 3: microelectrode insertion}

The patient is taken back to the operating room and a single burr hole is made. After coagulation of the dura, the patient is awakened. Five parallel microelectrodes are inserted, the central electrode corresponding to the calculated trajectory (the four others are situated $2 \mathrm{~mm}$ anteriorly, posteriorly, internally, and externally to the central electrode, respectively). Microrecordings and macrostimulation are then performed to determine the best trajectory and position of the definitive electrode-that is, the position where the greatest clinical improvement is obtained with the lowest stimulation intensity and the fewest side effects for a high level of stimulation intensity. The definitive electrode is then implanted and fixed to the skull. The contralateral electrode is usually implanted one or two weeks after the first one. Before implantation of the generator (Medtronic, Minneapolis, Minnesota) in the subclavicular position, all the patients have a postoperative MRI (frontal T2 weighted acquisitions and three dimensional Tl weighted acquisitions) to check the position of the definitive electrode. For each patient, postoperative MRI control showed that the projection of the active contact of the electrode was situated within the hyposignal corresponding to the STN.

\section{Clinical evaluation}

The unified Parkinson's disease rating scale score (part III) was used to evaluate the motor performances of the patients shortly before and six months after surgery. The median value of this score before surgery without L-Dopa was 48.5 $\left(\mathrm{Q}_{1}=44.0 ; \mathrm{Q}_{3}=58.0\right)$ and $15.0\left(\mathrm{Q}_{1}=10.5 ; \mathrm{Q}_{3}=21.5\right)$ with L-Dopa. After surgery, this score was $14.0\left(\mathrm{Q}_{1}=8.5\right.$; $\mathrm{Q}_{3}=18.5$ ) with stimulation and a $30 \%$ reduction in the L-Dopa dose.

\section{Experimental posturographic procedures}

The posturographic protocol was carried out in the balance control laboratory of the University Hospital of Nancy, France (Ministry of Health agreement for research).

For every postural test, the patients were studied in their "best on medication state" in the preoperative condition, and in "on stimulation, best on medication state" in the postoperative condition. The "off stimulation" situation was not tested to spare patients a too heavy and tiring procedure because of the difficulty in this situation both in the absolute condition and in posturographic testing.

\section{Static and dynamic posturographic tests}

All the patients underwent a static posturographic test on a vertical force platform (Toennies $\mathrm{GmbH}$, Freiburg, Germany) fitted with four pressure gauges, from which the centre of foot pressure (CoP) displacements were recorded. The subjects were requested to remain standing barefoot on the platform, as stable and relaxed as possible, feet $30^{\circ}$ apart and arms along the body, and, breathing normally, to stare at a mark placed horizontally on a wall two metres away.

The static test consisted of recording the CoP displacements for 20 seconds in the eyes open (EO) then in the eyes closed (EC) conditions. The statokinesigram obtained allowed measurement of the sway path (SP) and the area covered by the CoP movements, and sways in the anteriorposterior (AP) and lateral (Lat) axes were determined by vectorial analysis of CoP displacement (fig 1). Good postural 

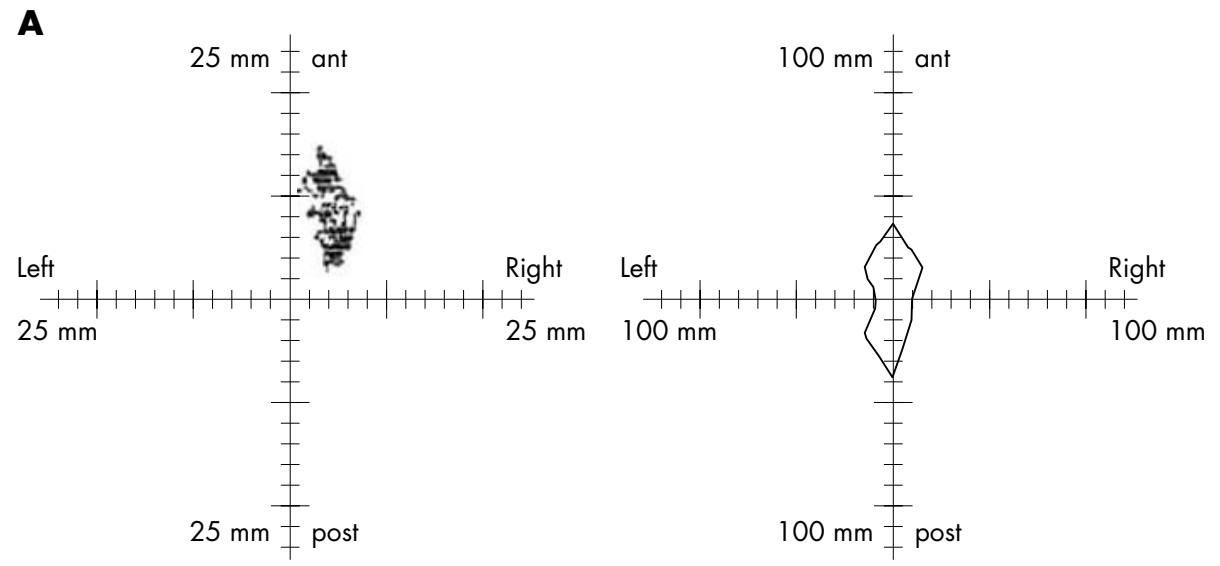

Way: $0.84 \mathrm{~cm} / \mathrm{s}$

Area: $0.27 \mathrm{~cm}^{2} / \mathrm{s}$

Ant/Post: $0.19 \mathrm{~cm} / \mathrm{s}$

Lateral: $\quad 0.04 \mathrm{~cm}^{2} / \mathrm{s}$

AP/lat: 4.28
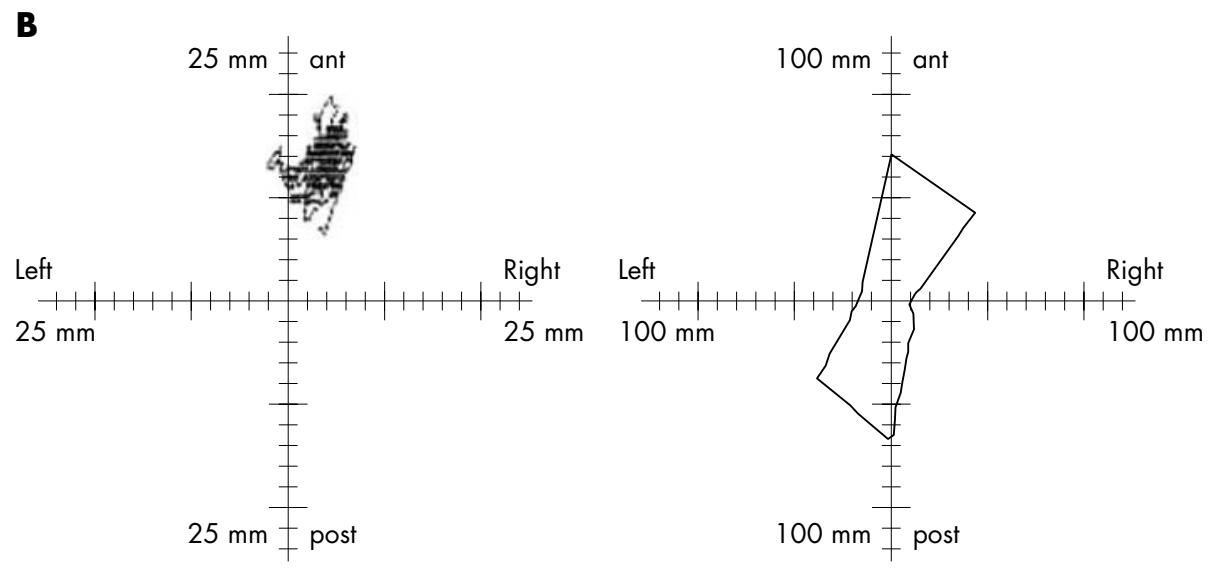

Way: $1.57 \mathrm{~cm} / \mathrm{s}$

Area: $0.54 \mathrm{~cm}^{2} / \mathrm{s}$

Ant/Post: $0.35 \mathrm{~cm} / \mathrm{s}$

AP/Lat: 5.38

Romberg (way): 1.86

Romberg (area): 2.03

Figure 1 Statokinesigram recordings from static tests performed with (A) eyes open and (B) eyes closed. The graphs on the left show the full recording of the centre of foot pressure (CoP) displacements, yielding the sway path (indicated as the way for the distance covered) and the area (of the surface covered). The graphs on the right are a vectorial analysis of the CoP displacements, and give the amplitude of the anterior-posterior (Ant/Post) and lateral sways.

control is mainly reflected by low values for the SP and area parameters, which convey information concerning the energy consumption required to ensure postural control and balance precision, respectively. ${ }^{35}$

The dynamic test comprised a 20 second motorised movement, which consisted of slow sinusoidal anteriorposterior oscillations of the support, with an amplitude of $4^{\circ}$ and a frequency of $0.5 \mathrm{~Hz}$ in the EO and EC conditions. The analysis of CoP displacements was carried out by comparing them with the sinusoid yielded by the movement of the platform or as fast Fourier transformations (FFT). FFT graphs were analysed by determining the frequencies and amplitudes of the different peaks. The presence of high frequency peaks, whatever the amplitude yielded, was not taken into account, because it was thought that they do not reflect the level of instability of the subject. Two typical recordings can be obtained (fig 2), which represent two different sensorimotor strategies based on different responses to destabilisation $^{36-38}$ (see Perrin et al for more details of the characteristics of the two sensorimotor strategies ${ }^{38}$ ). Type 1 recordings indicate high stability of the participant during the test. This pattern corresponds to a bottom-up regulation model, with the body oscillating like an inverted pendulum, involving mainly ankle movements. This type of sensorimotor strategy, termed "ankle strategy", is thought to be anticipatory. Type 2 recordings express the instability of the participant during the recording. This pattern corresponds to a top-down regulation model, favouring visual anchorage and vestibular reference systems, and involving movements of the main joints. This type of sensorimotor strategy, termed "hip strategy", necessitates reactional adjustments. Although these two types of sensorimotor strategies enabled the patients to maintain their balance during the test, falls, termed "stepping strategies", were defined by the participant reaching for the support or obviously leaning on the safety belt. 
A
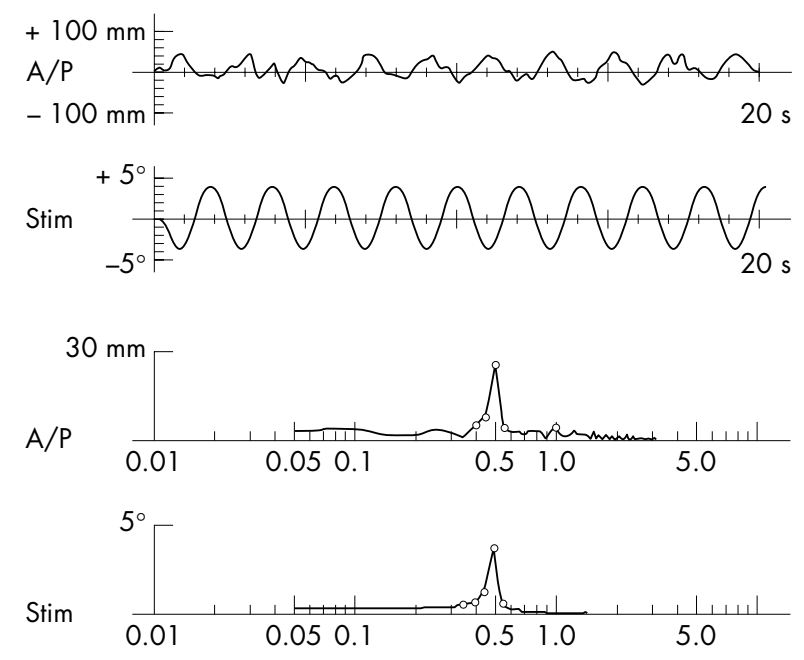

B
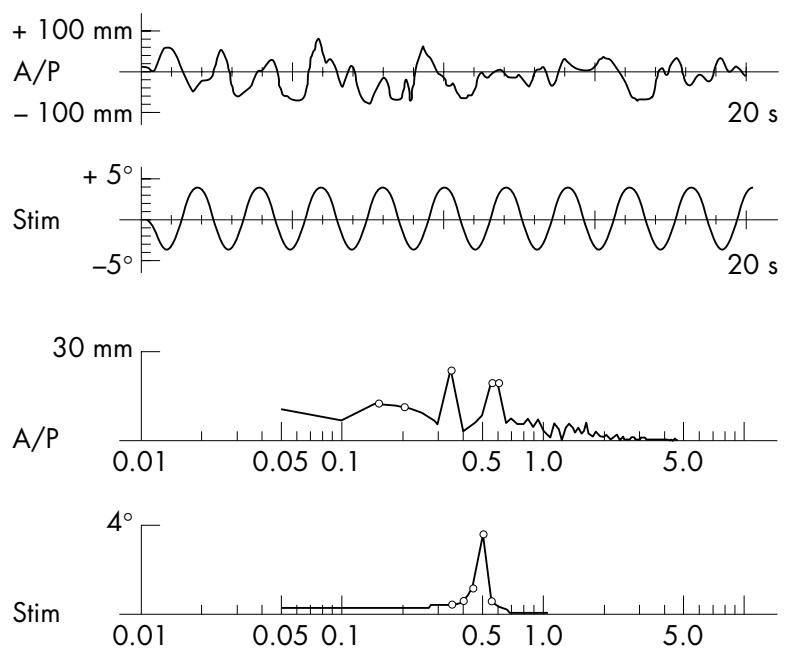

Figure 2 Centre of foot pressure (CoP) displacements recorded during a sinusoidal posturographic test with oscillations in the sagittal plane. Stim, sinusoidal platform movements. Typical recordings of CoP displacements (anterior-posterior (A/P)) and their fast Fourier transformation. The abscissa indicates the time that elapsed during the graphic recordings and the frequency in Hertz for the fast Fourier transformation graphs. Amplitude, on the ordinate scales, is expressed in millimetres for the subjects' movements and in degrees for the movement of the platform. (A) Type 1 recordings are homogeneous curves. (B) Type 2 recordings are non-homogeneous curves, characteristically irregular and representative of greater instability.

\section{Electromyographic analysis of posture} restabilisation after sudden toe up ramp rotation This consisted of sudden $4^{\circ}$ amplitude toe up ramp rotations of a posturography platform (Toennies GmbH, Freiburg, Germany) at a velocity of $50 \%$ second. Eight consecutive and unexpected toe up movements were performed. Integrated surface electromyographic (EMG) recordings of the tibialis anterior muscle (TA) and of the gastrocnemius medialis of the triceps surae muscle (TS) were performed simultaneously on both legs. Onset latencies of EMG activity after sudden tilt were calculated after identification of the onset and termination of each EMG component in each of eight consecutive single trials. EMG recordings, adjusted according to the height of each individual, were then averaged over eight runs and plotted. Three EMG responses were obtained..$^{39}$ First, a short latency response (SLR), collected on the TS, corresponds to a myotatic or stretch reflex. ${ }^{4041}$ Second, a medium latency response (MLR), also recorded on the TS, is the first of the balance correcting responses. ${ }^{41}$ Third, a long latency response (LLR), exclusively obtained on the antagonist of the stretched muscle, here TA, is the main balance correcting response, ${ }^{41}$ and is the only one that functionally stabilises posture. ${ }^{40}$

\section{Sensory organisation and adaptation tests}

All the subjects were also tested on a computerised dynamic posturography platform (Neurocom, Clackamas, Oregon, USA).

The sensory organisation test (SOT) evaluates the patient's ability to make effective use of visual, vestibular, and somatosensory inputs separately and to suppress sensory information that is inappropriate. To give inadequate information, somatosensory and visual cues are disrupted by using a technique commonly referred to as sway referenced. This technique involves tilting the support surface and/or the visual surround to follow directly the AP centre of gravity (CoG) sway of the subject. ${ }^{42}$ SOT was composed of six conditions (fig 3); the first two conditions provide a basic measurement of the subject's stability. The support is fixed and the subject's eyes are open (condition 1) or closed (condition 2). In condition 3, the support surface remains fixed while the subject stands, eyes open, in a sway referenced visual surround. From conditions 4 to 6 , somatosensory information is systematically disrupted (sway referenced) and vision is fixed (condition 4), absent (condition 5), or sway referenced (condition 6). The subject's task is to maintain an upright stance during the three 20 second trials of each condition with as little postural sway as possible and without moving the feet. The subjects wore a harness attached to the ceiling to prevent injury in the case of a fall. When the subject required the assistance of this harness or took a step, the test was rated as a fall.

An equilibrium score (ES) was calculated by comparing the patient's AP sway during each 20 second SOT trial to the maximal theoretical sway limits of stability $\left(8.5^{\circ}\right.$ anteriorly and $4^{\circ}$ posteriorly). A score of 100 represents no sway, whereas 0 indicates sway that exceeds the limit of stability, resulting in a fall. $\mathrm{Cl}^{\mathrm{ES}}$ was the averaged equilibrium score of the three trials in condition $1, \mathrm{C}^{\mathrm{ES}}$ in condition $2, \mathrm{C}^{\mathrm{ES}}$ in condition 3, $\mathrm{C}^{\mathrm{ES}}$ in condition $4, \mathrm{C}^{\mathrm{ES}}$ in condition 5, and $\mathrm{C}^{\mathrm{ES}}$ in condition 6. A composite equilibrium score $\left(\mathrm{C}^{\mathrm{ES}}\right)$ was calculated by independently averaging the scores for conditions 1 and 2, then adding to the equilibrium scores from each trial of sensory conditions 3, 4, 5, and 6, and finally dividing that sum by the total number of trials. Each ES was adjusted on $\mathrm{Cl}^{\mathrm{ES}}$ to identify the significance of each sensory system influencing postural control: the $\mathrm{C}^{\mathrm{ES}} \mathrm{Cl}^{\mathrm{ES}}$ ratio represented the somatosensory contribution to postural control $\left(\mathrm{R}^{\mathrm{SOM}}\right)$, the $\mathrm{C}^{\mathrm{ES} /} \mathrm{Cl}^{\mathrm{ES}}$ ratio the visual contribution $\left(\mathrm{R}^{\mathrm{VIS}}\right)$, and the $\mathrm{C}^{\mathrm{ES} /} \mathrm{Cl}^{\mathrm{ES}}$ ratio the vestibular contribution $\left(\mathrm{R}^{\mathrm{VEST}}\right)$. Thus, the ability to rely on vision, even if inadequate, was evaluated by comparing the sway referenced visual surround with the absence of vision $\left(\left(\mathrm{C} 3^{\mathrm{ES}}+\mathrm{C}^{\mathrm{ES}}\right) /\right.$ $\left.\left(\mathrm{C} 2^{\mathrm{ES}}+\mathrm{C} 5^{\mathrm{ES}}\right)\right)$, which conveys visual preference $\left(\mathrm{R}^{\mathrm{PREF}}\right)$. Thus, the ability to manage altered proprioceptive inputs $\left(\mathrm{R}^{\mathrm{PMAN}}\right)$ was evaluated by comparing all the sway referenced platform conditions with all the fixed platform conditions $\left(\left(\mathrm{C} 4^{\mathrm{ES}}+\mathrm{C} 5^{\mathrm{ES}}+\mathrm{C} 6^{\mathrm{ES}}\right) /\left(\mathrm{C} 1^{\mathrm{ES}}+\mathrm{C} 2^{\mathrm{ES}}+\mathrm{C} 3^{\mathrm{ES}}\right)\right) .^{43}$ Moreover, the relative amounts of ankle movement (ankle strategy) and hip movement (hip strategy) that the individual used to maintain balance during each procedure were calculated. Exclusive use of the ankle strategy to maintain equilibrium resulted in a score of 100. Exclusive use of the hip strategy yielded a score close to 0 . Strategy scores (SS) between these 

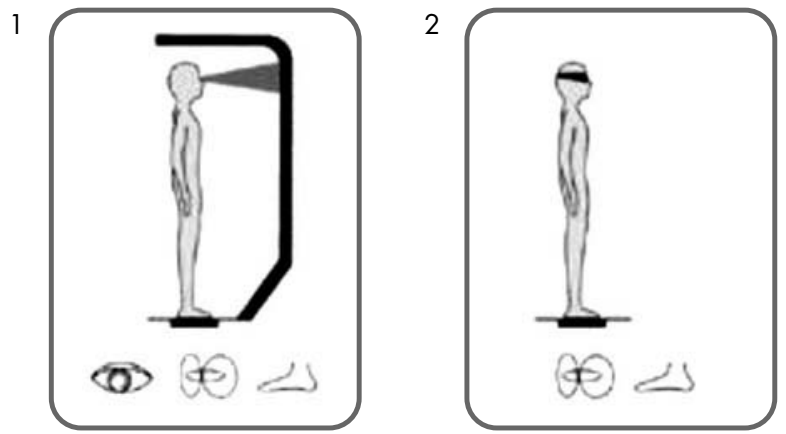

4

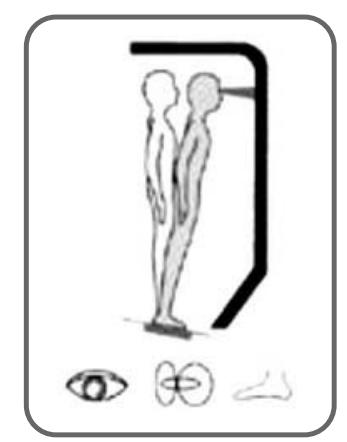

5

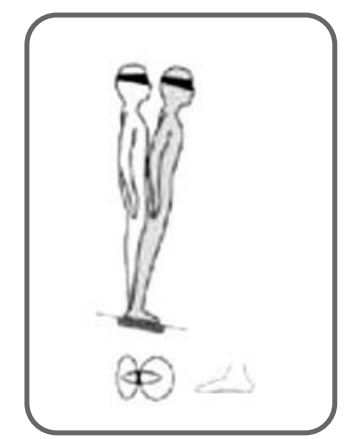

3

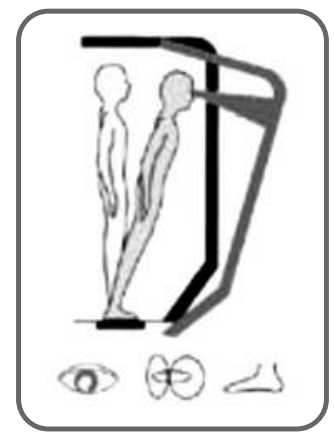

Figure 3 The six conditions of the sensory organisation test (EquiTest; Neurocom, Clackamas, Oregon, USA).

Conditions 1-3 were performed on a fixed platform with eyes open, eyes closed, and vision sway referenced, respectively. Conditions 4-6 were performed on a sway referenced platform with eyes open, eyes closed, and vision sway referenced, respectively.

6

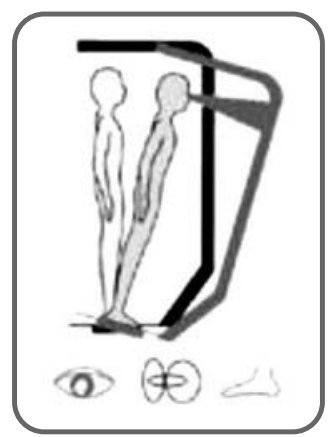

two extremes represented a combination of the two strategies. $\mathrm{Cl}^{\mathrm{SS}}$ represented the averaged strategy score of the three trials in condition $1, \mathrm{C} 2{ }^{\mathrm{SS}}$ in condition $2, \mathrm{C}^{\mathrm{SS}}$ in condition 3, $\mathrm{C} 4^{\mathrm{SS}}$ in condition $4, \mathrm{C} 5^{\mathrm{SS}}$ in condition 5 , and $\mathrm{C}^{\mathrm{SS}}$ in condition 6 . A composite strategy score $\left(\mathrm{C}^{\mathrm{SS}}\right)$ was calculated by independently averaging the scores for conditions 1 and 2, then adding to the equilibrium scores from each trial of sensory conditions 3, 4, 5, and 6, and finally dividing that sum by the total number of trials.

The adaptation test (ADT) evaluated the automatic postural response provoked by unexpected support surface perturbations. The two ADT conditions, toes up and toes down, consisted of rotations or movements that cause the individual's toes to go up or down. The axis of the movement was at ankle level. Five trials for each rotation were applied. Rotations lasted 0.4 seconds and were uniform in amplitude for all of the trials and individuals. The CoP displacement and the vertical component of the CoG were calculated to define the sway value for every trial of both conditions. The toe up $\mathrm{ADT}\left(\mathrm{TU}^{\mathrm{ADT}}\right)$ parameter represented the average sway in the toe up condition, whereas the toe down $\mathrm{ADT}\left(\mathrm{TD}^{\mathrm{ADT}}\right.$ ) parameter represented the average sway in the toe down condition. A composite ADT parameter $\left(\mathrm{C}^{\mathrm{ADT}}\right)$ was calculated to define the global adaptation of the motor system.

\section{Statistical analysis}

Statistical analysis was carried out using Statview Software (Abacus, Berkeley, California, USA). Non-parametric tests were used because of the relatively small sample size. The McNemar $\chi^{2}$ test was performed for the dynamic posturographic parameters (distribution comparison), and the Wilcoxon test ( $\mathrm{z}$, two-two comparison) for all the other clinical and posturographic parameters. A probability level of $\mathrm{p}<0.05$ was used as an indicator of significance in all the analyses.

\section{RESULTS}

STN stimulation improved balance control in all patients as measured by the main posturographic parameters.
The static posturographic tests (table l) showed that patients displayed lower SP, area, and Lat postoperatively than preoperatively, both in the EO and EC conditions. No significant differences were seen for the AP parameter in either the EO or EC condition

In the preoperative dynamic test, only one of the 12 patients fell in the EO condition whereas 10 patients fell in the EC condition. Although STN stimulation did not improve stance maintenance in the EO condition, it enabled nine of the 10 patients who fell preoperatively in the EC condition to regain balance $\left(\chi^{2}=9\right.$; degrees of freedom $(\mathrm{df}), \mathrm{l}$; $\mathrm{p} \leqslant 0.01)$. In addition, STN stimulation improved the stability of postural control in the EO condition, with four of the 11 patients being able to stand and change from type 2 strategy to type $1\left(\chi^{2}=4 ; \mathrm{df}, \mathrm{l} ; \mathrm{p} \leqslant 0.05\right)$.

The electromyographic analysis revealed a lower SLR in the postoperative condition $(\mathrm{z}=-2.666 ; \mathrm{p}=0.007)$, whereas the MLR and LLR were not significally different between the preoperative and postoperative conditions.

The SOT analysis (table 2) revealed that the postoperative ES values were greater than the preoperative values, particularly for $\mathrm{C} 3^{\mathrm{ES}}, \mathrm{C}^{\mathrm{ES}}, \mathrm{C}^{\mathrm{ES}}$, and $\mathrm{C}^{\mathrm{ES}}$. No significant differences were found for $\mathrm{Cl}^{\mathrm{ES}}$ and $\mathrm{C}_{2}{ }^{\mathrm{ES}}$ between the preoperative and postoperative conditions, whereas a statistical tendency was noted for $\mathrm{C}^{\mathrm{ES}}{ }^{\mathrm{S}}$. With regard to the contribution of sensory cues to balance, $\mathrm{R}^{\mathrm{VIS}}$ and $\mathrm{R}^{\mathrm{VEST}}$ improved after STN stimulation, but no significant differences were seen for $\mathrm{R}^{\mathrm{SOM}}$. Moreover, with regard to the ratios indicating the management of sensorial conflict, $\mathrm{R}^{\text {PMAN }}$ improved after STN stimulation, whereas $\mathrm{R}^{\mathrm{PREF}}$ was unchanged. The changes in the SS values were similar in nature to those of the ES values, with significant differences being observed for $\mathrm{C}^{\mathrm{SS}}(\mathrm{z}=-2.157 ; \mathrm{p}=0.031)$ and $\mathrm{C}^{\mathrm{SS}}$ $(\mathrm{z}=-2.275 ; \mathrm{p}=0.023)$, and a tendency close to significance for $\mathrm{C}^{\mathrm{SS}}(\mathrm{z}=-1.669 ; \mathrm{p}=0.091)$.

The ADT analysis showed that postoperatively sways were less important than preoperatively, both for $\mathrm{TU}^{\mathrm{ADT}}(\mathrm{z}=$ $-2.223 ; \mathrm{p}=0.026), \mathrm{TD}^{\mathrm{ADT}}(\mathrm{z}=-2.824 ; \mathrm{p}=0.005)$, and for $\mathrm{C}^{\mathrm{ADT}}(\mathrm{z}=-2.981 ; \mathrm{p}=0.003)$. 
Table 1 Results of static tests

\begin{tabular}{|c|c|c|c|}
\hline & $\begin{array}{l}\text { Preoperative test } \\
\text { Median }\left(Q_{1}, Q_{3}\right)\end{array}$ & $\begin{array}{l}\text { Postoperative test } \\
\text { Median }\left(Q_{1}, Q_{3}\right)\end{array}$ & $\begin{array}{l}\text { Significance } \\
\text { (Wilcoxon } z \text { and } p \text { values) }\end{array}$ \\
\hline \multicolumn{4}{|l|}{ EO condition } \\
\hline Sway path & $2.00(1.25,2.53)$ & $1.33(0.55,1.90)$ & $z=-2.197 ; p=0.028$ \\
\hline Area & $1.32(0.45,2.53)$ & $0.34(0.24,1.24)$ & $z=-2.510 ; p=0.012$ \\
\hline AP sways & $0.30(0.20,0.58)$ & $0.31(0.17,0.47)$ & $z=-0.533 ; \mathrm{NS}$ \\
\hline Lateral sways & $0.17(0.08,0.26)$ & $0.09(0.06,0.11)$ & $z=-2.039 ; p=0.042$ \\
\hline \multicolumn{4}{|l|}{ EC condition } \\
\hline Sway path & $2.37(1.55,5.85)$ & $1.70(1.37,2.01)$ & $z=-2.589 ; p=0.010$ \\
\hline Area & $1.77(0.73,4.01)$ & $0.56(0.43,1.09)$ & $z=-2.589 ; p=0.010$ \\
\hline AP sways & $0.44(0.34,0.84)$ & $0.44(0.35,0.52)$ & $\mathrm{z}=-0.981 ; \mathrm{NS}$ \\
\hline Lateral sways & $0.15(0.09,0.24)$ & $0.08(0.07,0.12)$ & $z=-2.667 ; p=0.008$ \\
\hline
\end{tabular}

\section{DISCUSSION}

Our study shows that STN stimulation, in combination with L-Dopa treatment, reduces postural instability by increasing motor abilities and specific postural related mechanisms, leading to a reduction in falls. Balance precision is improved, even in more difficult situations, both during the EC condition and in sensory challenged conditions. The patients' sensorimotor strategies were of better quality and they displayed more appropriate strategies, using better proprioception in relation to the other sensors. In situations of sensorial conflict, the patients were able to adapt their balance more accurately, especially in proprioceptive management situations, suggesting an improvement in central information processing.

In the traditional view of postural control, balance during quiet stance and its adaptation to the environment is based on background postural tone and on postural reflexes, which are generated by the vestibular, visual, and somatosensory systems ${ }^{44}$ and involve higher levels of control ${ }^{45}$ In our study, static posturographic evaluation showed an improvement in performance when stimulation was added to L-Dopa treatment. This increase in balance precision and reduction in sways after surgery requires the vestibulo-spinal loop to be more effective. According to the integrity of peripheral information in $\mathrm{PD},{ }^{2}$ this improvement can be explained by the fact that messages generated by vestibular nuclei can be managed by peripheral effectors as a result of a reduction in muscle rigidity. This decrease in muscle stiffness could also be the cause of the improvement in myotatic reflex latency and sways during the adaptation test. This test showed that STN stimulation allowed the fine tuning of postural response synergies. This type of testing requires more peripheral information, especially from the eyes and vestibular semicircular canals, and a complementary hypothesis explaining postural improvement after surgery could be related to the reduction in the misinterpretation of visual information seen in PD by STN stimulation. ${ }^{11}$ Nevertheless, it seems that the deficit in central information processing has a greater impact on balance disorders in PD than the quality of peripheral information, and that STN stimulation improves central integration and reduces induced sensorial conflicts.

As suggested by Bronstein et al, ${ }^{4}$ there is a reduced capacity in PD to weigh up and adapt to the different sensory inputs assessing changes in the environment, and this trouble in managing information was confirmed in our study during the preoperative evaluation, particularly for the more disruptive tests, such as dynamic and sensorial conflict situations and the EC condition. The preoperative dynamic test results showed that proprioception is used less often in $\mathrm{PD}$ and is associated with misinterpretation of vision, as suggested by the difficulty in maintaining stance in the EC condition test and the elaboration of reactional sensorimotor strategies in the EO test. This hypothesis is reinforced by the single or complex vestibular, proprioceptive, and visual ratios observed with the SOT test, which suggest difficulty in processing these different afferences. The increase in the dynamic and even the general control of balance after L-Dopa treatment is complimented with STN stimulation can be explained by the improved use of proprioception and vision and, thus, a reduction in sensorial conflicts at the central information processing level. The quality of the postural sensorimotor strategies also improved, as if the subjects were able to provide more adapted responses to destabilisation, using the ankle joint more to regulate balance than the other

Table 2 Sensory organisation test results

\begin{tabular}{|c|c|c|c|}
\hline & $\begin{array}{l}\text { Preoperative test } \\
\text { Median }\left(Q_{1}, Q_{3}\right)\end{array}$ & $\begin{array}{l}\text { Postoperative test } \\
\text { Median }\left(Q_{1}, Q_{3}\right)\end{array}$ & $\begin{array}{l}\text { Significance (Wilcoxon } z \text { and } \\
\text { p values) }\end{array}$ \\
\hline \multicolumn{4}{|c|}{ Equilibrium scores } \\
\hline $\mathrm{Cl}^{\mathrm{ES}}$ & $91.83(90.00,93.34)$ & $90.67(90.17,92.84)$ & $z=-0.356 ; N S$ \\
\hline $\mathrm{C} 2^{\mathrm{ES}}$ & $88.00(86.00,90.50)$ & $88.17(86.33,89.83)$ & $z=-0.196 ; N S$ \\
\hline $\mathrm{C}^{\mathrm{ES}}$ & $83.50(76.83,89.67)$ & $87.84(84.17,90.84)$ & $z=-2.197 ; p=0.028$ \\
\hline $\mathrm{C} 4^{\mathrm{ES}}$ & $73.17(45.67,84.00)$ & $78.00(72.83,82.00)$ & $z=-1.883 ; p=0.060$ \\
\hline $\mathrm{C} 5^{\mathrm{ES}}$ & $10.17(0.00,42.50)$ & $59.67(40.17,68.84)$ & $z=-2.845 ; p=0.004$ \\
\hline $\mathrm{C}^{\mathrm{ES}}$ & $18.50(0.00,68.84)$ & $59.50(45.00,72.50)$ & $z=-2.824 ; p=0.005$ \\
\hline $\mathrm{C}^{\mathrm{ES}}$ & $54.00(44.50,65.00)$ & $73.00(67.00,78.50)$ & $z=-2.934 ; p=0.003$ \\
\hline \multicolumn{4}{|l|}{ Ratios (R) } \\
\hline $\mathrm{R}^{\mathrm{SOM}}$ & $0.96(0.95,0.98)$ & $0.97(0.96,0.99)$ & $z=-0.356 ; N S$ \\
\hline $\mathrm{R}^{\mathrm{VIS}}$ & $0.82(0.49,0.90)$ & $0.87(0.81,0.92)$ & $z=-2.353 ; p=0.019$ \\
\hline $\mathrm{R}^{\mathrm{VEST}}$ & $0.11(0.00,0.44)$ & $0.66(0.45,0.78)$ & $z=-2.845 ; p=0.004$ \\
\hline $\mathrm{R}^{\text {PREF }}$ & $0.97(0.83,1.14)$ & $1.02(0.97,1.07)$ & $z=-0.578 ; N S$ \\
\hline$R^{\text {PMAN }}$ & $0.39(0.26,0.61)$ & $0.76(0.61,0.83)$ & $z=-2.981 ; p=0.003$ \\
\hline
\end{tabular}

$\mathrm{C} 1-6$, conditions $1-6 ; C^{E S}$, composite equilibrium score; ES, equilibrium score; NS, not significant; Q1, first quartile; Q3, third quartile. 
joints. Preferential use of the ankle joint to regulate posture is known to increase the quality of balance and to reduce falls. ${ }^{46}$ It leads to balance control from moving support and so an anticipation of destabilising movements by the elaboration of bottom-up strategies. This type of sensorimotor strategy necessitates adequate information processing, especially at centres that automatically elaborate movement. STN stimulation combined with L-Dopa treatment allowed the basal ganglia to function again, and the feedback generated during movement permitted permanent adjustments at these centres, and therefore better adaptation of the subject to stimulation. A combination of these two treatments allowed better central processing of the sensorial inputs and thus better central postural adaptation.

Our study of the influence of current treatment of postural control in PD has allowed a better understanding of its balance mechanisms. It is well known that L-Dopa restores dopaminergic pathway functionality in the basal ganglia. ${ }^{46}$ According to the model proposed by Alexander and Crutcher, ${ }^{47}$ L-Dopa decreases the negative output of the thalamus to the motor cortex, which explains the improvement in akinesia and rigidity. Nevertheless, the effect of L-Dopa on postural control is still controversial, because postural instability and falls are thought to respond poorly to dopaminergic treatment. ${ }^{48}$ Mild improvements were reported by Bejjani et al, ${ }^{22}$ probably because of the reduction in rigidity and motor facilitation. However, these partial L-Dopa effects on balance show that dynamic postural control mechanisms in PD are more complex and probably not only influenced by dopaminergic pathways. The existence of non-dopaminergic lesions in PD could explain why some symptoms of the disease are poorly improved by L-Dopa. ${ }^{46}$ Postural control regulation might also depend on non-dopaminergic pathways that are defective in PD. In addition, it has even been reported that L-Dopa treatment can cause balance impairment in $\mathrm{PD}^{24}{ }^{25}$ and this finding highlights the fact that L-Dopa treatment could restore motor function but not central control, which is not under dopaminergic influence. The disproportion between motor capacity and central control inaccuracy could lead to an impairment of postural performance. STN stimulation is known to reproduce the effects of L-Dopa on motor symptoms such as bradykinesia and rigidity in the same proportion. ${ }^{30}$ Clinical and posturographic evaluations have shown that the improvement in balance is greater with only STN stimulation than with L-Dopa alone. ${ }^{31}$ Moreover, a synergistic effect of STN stimulation combined with L-Dopa treatment on the axial signs of the disease ${ }^{22}$ and gait $^{49}$ has been described. Our study confirms this synergistic effect, because postural adaptation was improved when STN stimulation was used in conjunction with L-Dopa compared with L-Dopa treatment alone. Our study also confirms that postural control and motor signs are ruled by different pathways, and that postural regulation depends on the nondopaminergic system. The explanation for this non-dopaminergic postural regulation may be found at the mesencephalic level.

Of all the upper brainstem structures, the pedonculopontine nucleus (PPN) is of most interest in the study of postural regulation mechanisms. Pahapill and Lozano ${ }^{50}$ highlighted that this mesencephalic nucleus is divided into two parts-the pars compacta, comprising cholinergic neurones, and the pars dissipatus, comprising glutamatergic neurones-with inputs from the spinal cord and basal ganglia, ascending projections on the thalamus and STN, and descending projections on the deep cerebellar nuclei and spinal cord. Accordingly, PPN should play the role of a relay station providing the basal ganglia with information for posture modulation, and the basal ganglia might generate an overactive inhibitory outflow to the PPN in PD. ${ }^{50}$ STN stimulation would block these overactive connections and restore the normal function of the system. ${ }^{49}$ However, the overactive influence of the basal ganglia on the PPN is probably not the only pathological mechanism leading to postural instability in PD. Indeed, the non-dopaminergic system must initially be deficient because otherwise L-Dopa alone would significantly improve postural stability, and there would be no synergistic effect with stimulation. As a result, STN stimulation separately influences both the dopaminergic and non-dopaminergic pathways, allowing synergistic postural improvement.

In conclusion, our study confirms that the addition of STN stimulation to L-Dopa treatment improves basic static postural control in PD. Moreover, in complex balance situations, such as dynamic tests and sensorial conflict, postural adaptation strategies are of better quality. STN stimulation also has a synergistic effect with L-Dopa in the treatment of postural abnormalities, and STN stimulation influences both the dopaminergic and non-dopaminergic pathways of postural control.

\section{Authors' affiliations}

S Colnat-Coulbois, J Auque, Department of Neurosurgery, University Hospital of Nancy, Nancy 54000, France

G C Gauchard, National Institute for Health and Medical Research (INSERM), [EP] ${ }^{2} R$, Faculty of Medicine, Vandoeuvre-lès-Nancy 54500, and Balance Control and Motor Performance, UFR STAPS, Henri Poincaré-Nancy 1 University, Villers-lès-Nancy 54600, France

L Maillard, G Barroche, H Vespignani, Department of Neurology, University Hospital of Nancy

P P Perrin, National Institute for Health and Medical Research (INSERM), $[E P]^{2} R$, Faculty of Medicine, Vandoeuvre-lès-Nancy, and Balance Control and Motor Performance

Competing interests: none declared

\section{REFERENCES}

1 Brown P, Steiger MJ. Basal ganglia gait disorders. In: Bronstein AM, Brandt TH, Woollacott $M$, eds. Balance, posture and gait. London: Arnold, 1996:156-67.

2 Pastor MA, Day BL, Marsden CD. Vestibular induced postural responses in Parkinson's disease. Brain 1993;116:1177-90.

3 Martin JP. The basal ganglia and posture. London: Pitman, 1967.

4 Bronstein AM, Hood JD, Gresty MA, et al. Visual control of balance in cerebellar and parkinsonian syndromes. Brain 1990;113:767-79.

5 Rickards C, Cody FWJ. Proprioceptive control of wrist movements in Parkinson's disease. Reduced muscle vibration-induced errors. Brain 1997; 120:977-90.

6 Khudados E, Cody FW, O'Boyle DJ. Proprioceptive regulation of voluntary ankle movements, demonstrated using muscle vibration, is impaired by Parkinson's disease. J Neurol Neurosurg Psychiatry 1999;67:504-10.

7 Frank JS, Horak FB, Nutt J. Centrally initiated postural adjustments in parkinsonian patients on and off levodopa. J Neurophysiol 2000;84:2440-8.

8 Bloem BR, Van Vugt JP, Beckley DJ. Postural instability and falls in Parkinson's disease. Adv Neurol 2001;87:209-23.

9 Marsden CD. The mysterious motor function of the basal ganglia: the Robert Wartenberg lecture. Neurology 1982;32:514-39.

10 Horak FB, Nutt JG, Nashner LM. Postural inflexibility in parkinsonian subjects. J Neurol Sci 1992;111:46-58.

11 Bronte-Stewart HM, Minn AY, Rodrigues K, et al. Postural instability in idiopathic Parkinson's disease: the role of medication and unilateral pallidotomy. Brain 2002;125:2100-14.

12 Girotti F, Soliveri P. Cognitive and behavioral disturbances in Parkinson's disease. Neurol Sci 2003;24(suppl 1):S30-1.

13 Lewis SJ, Dove A, Robbins TW, et al. Cognitive impairments in early Parkinson's disease are accompanied by reductions in activity in frontostriatal neural circuitry. J Neurosci 2003;23:6351-6.

14 Vingerhoets G, Verleden S, Santens $P$, et al. Predictors of cognitive impairment in advanced Parkinson's disease. I Neurol Neurosurg Psychiatry 2003;74:793-6.

15 Dick JPR, Rothwell JC, Berardelli A, et al. Associated postural adjustments in Parkinson's disease. J Neurol Neurosurg Psychiatry 1986:49:1378-85.

16 Kensinger EA, Shearer DK, Locascio JJ, et al. Working memory in mild Alzheimer's disease and early Parkinson's disease. Neuropsychology 2003;17:230-9.

17 Testa D, Fetoni V, Soliveri P, et al. Cognitive and motor performance in multiple system atrophy and Parkinson's disease compared. Neuropsychologia 1993;31:207-10.

18 Hamani C, Lozano AM. Physiology and pathophysiology of Parkinson's disease. Ann N Y Acad Sci 2003;991:15-21. 
19 Koller WC, Glatt S, Vetere-Overfield B, et al. Falls and Parkinson's disease. Clin Neuropharmacol 1989;12:98-105.

20 Adkin AL, Frank JS, Jog MS. Fear of falling and postural control in Parkinson's disease. Mov Disord 2003; 18:496-502.

21 Azulay JP, Mesure S, Amblard B, et al. Increased visual dependence in Parkinson's disease. Percept Mot Skills 2002;95:1106-14.

22 Beijani BP, Gervais D, Arnulf I, et al. Axial parkinsonian symptoms can be improved: the role of levodopa and bilateral subthalamic stimulation. J Neurol Neurosurg Psychiatry 2000;68:595-600.

23 Burn DJ. The effect of deep brain stimulation and levodopa on postural sway in subjects with Parkinson's disease. J Neurol Neurosurg Psychiatry 2002;73:240

24 O'Suilleabhain P, Bullard J, Dewey RB. Proprioception in Parkinson's disease is acutely depressed by dopaminergic medications. J Neurol Neurosurg Psychiatry 2001;71:607-10.

25 Rocchi L, Chiari L, Horak FB. Effects of deep brain stimulation and levodopa on postural sway in Parkinson's disease. J Neurol Neurosurg Psychiatry 2002;73:267-74

26 Mandybur G, King WM, Moore K. Stereotactic posteroventral pallidotomy improves balance control as assessed by computerized posturography. Stereotact Funct Neurosurg 1999;79:233-40.

27 Roberts-Warrior D, Overby A, Jankovic J, et al. Postural control in Parkinson's disease after unilateral posteroventral pallidotomy. Brain 2000;123:2141-9.

28 Jankovic J, Lai EC, Ondo WG, et al. Effects of pallidotomy on gait and balance. Adv Neurol 2001;87:271-81.

29 Melnick ME, Dowling GA, Aminoff MJ, et al. Effect of pallidotomy on postural control and motor function in Parkinson disease. Arch Neurol 1999:56:1361-5.

30 Krack $\mathbf{P}$, Pollak $P$, Limousin $P$, et al. Subthalamic nucleus or internal part of pallidal stimulation in young onset Parkinson's disease. Brain 1998; 121:451-7

31 Benabid AL, Koudsie A, Benazzouz A, et al. Subthalamic stimulation for Parkinson's disease. Arch Med Res 2000;31:282-9.

32 Welter ML, Houeto JL, Tezenas du Montel S, et al. Clinical predictive factors of subthalamic stimulation in Parkinson's disease. Brain 2002;125:575-83.

33 Maurer C, Mergner T, Xie J, et al. Effect of chronic bilateral subthalamic nucleus (STN) stimulation on postural control in Parkinson's disease. Brain 2003;126:1146-63.

34 Beijani BP, Dormont D, Pidoux B, et al. Bilateral subthalamic stimulation for Parkinson's disease by using three dimensional stereotactic magnetic resonance imaging and electrophysiological guidance. J Neurosurg 2000;92:615-25.

35 Toupet M, Gagey PM, Heuschen S. Vestibular patients and aging subjects lose use of visual input and expend more energy in static postural control. In:
Vellas $B$, Toupet $M$, Rubenstein $L$, et al, eds. Falls, balance and gait disorders in the elderly. Paris: Elsevier, 1992:183-98.

36 Horak FB, Nashner LM. Central programming of postural movements: adaptation to altered support-surface configuration. J Neurophysiol 1986:55:1369-81.

37 Gauchard GC, Lascombes P, Kuhnast M, et al. Influence of different types of progressive idiopathic scoliosis on static and dynamic postural control. Spine 2001;26:1052-8

38 Perrin PP, Deviterne D, Hugel F, et al. Judo, better than dance, develops sensorimotor adaptabilities involved in balance control. Gait Posture 2002; 15:187-94.

39 Diener HC, Dichgans J. On the role of vestibular, visual and somatosensory information for dynamic postural control in humans. In: Pompeiano $\mathrm{O}$ Allum JHJ, eds. Progress in brain research, Vol. 76. Amsterdam: Elsevier, 1988:253-62.

40 Diener HC, Dichgans J, Bootz F, et al. Early stabilization of human posture after sudden disturbance: influence of rate and amplitude of displacement. Exp Brain Res 1984;56:126-34.

41 Allum JHJ, Shepard NT. An overview of the clinical use of dynamic posturography in the differential diagnosis of balance disorders. J Vestib Res 1999:9:223-52.

42 Nashner LM. Dynamic posturography in the diagnosis and management of dizziness and balance disorders. Neurol Clin 1990;8:331-49.

43 Black FO, Paloski WH, Doxey-Gasway DD, et al. Vestibular plasticity following orbital spaceflight: recovery from postflight postural instability. Acta Otolaryngol (Stockh) 1995;520(suppl):450-4

44 Massion J, Woollacott MH. Posture and equilibrium. In: Bronstein AM, Brandt TH, Woollacott $M$, eds. Balance, posture and gait. London: Arnold, 1996:1-18.

45 Dietz V. Human neuronal control of automatic functional movements: interaction between central programs and afferent input. Physiol Rev 1992;72:33-69.

46 Agid Y. Parkinson's disease: physiopathology. Lancet 1991;337:1321-4

47 Alexander GE, Crutcher MD. Functional architecture of basal ganglia circuits: neural substrates of parallel processing. Trends Neurosci 1990;13:266-71

48 Bonnet AM, Loria Y, Saint-Hilaire MH, et al. Does long-term aggravation of Parkinson's disease result from non-dopaminergic lesions? Neurology 1987;37:1539-42.

49 Faist M, Xie J, Kurz D, et al. Effect of bilateral subthalamic nucleus stimulation on gait in Parkinson's disease. Brain 2001;124:1590-600.

50 Pahapill PA, Lozano AM. The pedonculopontine nucleus and Parkinson's disease. Brain 2000;123:1767-83. 